\title{
Macau gaming industry scare research - A public finance perspective Yu Song ${ }^{1, a,{ }^{*}}$, Songhong Chen ${ }^{2, b}$ \\ ${ }^{1,2}$ Macau University of science and technology, Avenida Wai Long, Taipa, Macau \\ a ysong@must.edu.mo, bshchen@must.edu.mo \\ ${ }^{*}$ Corresponding author
}

Keywords: Gaming industry, Scare, Public finance.

\begin{abstract}
Since the opening of the gambling rights, Macau's economic development has achieved remarkable results. The rapid development of the gaming industry has led to the growth of fiscal revenue. In this paper, a linear regression model, a grey econometric hybrid model and an ARIMA model are constructed to predict, and then three models are given different weights to construct a comprehensive forecasting model to achieve higher prediction accuracy. Through quantitative analysis, we deeply analyzed the impact of gambling tax on public finance, predicted the trend of future public expenditure in Macau, measured the public income needed to meet the expenditure, and predicted the future development scale of the gaming industry from the perspective of public finance.
\end{abstract}

\section{Introduction}

Since the reunification, especially since the opening of the gambling rights, Macau's economic development has achieved remarkable results. The rapid development of the gaming industry has led to the growth of fiscal revenue, the total amount of fiscal expenditure has also increased, and the financial situation has continued to improve. The improvement of social economy laid the foundation. Gaming taxation plays an important role in the operation of the Macau SAR government and the realization of social redistribution, enabling it to have sufficient financial resources to invest in infrastructure construction, science, education, culture and social welfare, and promote the smooth and orderly operation of Macau society. Realize social fairness and justice. Therefore, it is necessary to analyze the impact of gambling tax on public finance from a quantitative perspective, predict the trend of future public expenditure in Macau, and measure the public income needed to meet the expenditure. Many studies have discussed the impact of the size of the Macau gaming industry on the economy $[1,5,6]$. The relevant research on Macau's finance has also attracted a lot of research interest [2, 4, 7, 8, 9], using fiscal revenue to predict the scale of the gaming industry. The research is more common. In this paper we constructed a linear regression model, gray econometric model and the hybrid model ARIMA models (Autoregressive Integrated Moving Average Model, referred to as ARIMA) to predict, and then given different weights of the three models in order to re-construct a comprehensive model to predict higher prediction accuracy Finally, three different scenarios are assumed, and the established four models are used to measure and predict the impact of gambling tax on public finance in different situations.

\section{Research method}

\subsection{Linear regression model (model A)}

The linear regression model is a model for mathematical statistical analysis of influencing factors and predicted objects with causal relationships. A linear regression model can be used to process the linear relationship between a dependent variable and an independent variable, establish a linear model between variables and evaluate and predict based on the model. According to the analysis in the previous section, there is a strong correlation between the gambling tax and various fiscal revenues and expenditures. Based on this, we establish a linear regression model between gambling tax and public revenue and expenditure as follows: 


$$
y_{i}=c+\alpha x_{\mathrm{t}}
$$

Where: $y_{i}$ is public income and expenditure; c is a constant term; to fit the coefficient; $x$ is the betting duty income; $t$ is the data time point.

\subsection{Grey economic quantity hybrid model (model B)}

We use the annual data from 2002 to 2016 in Macau, establish a grey Verhulst model based on the grey theory and calculate the relevant simulation data, then use the least squares method to fit the simulation data, establish a grey economic quantity hybrid model and predict the gambling tax on public revenue and the impacts of spending. The gray model can analyze the difference between the development factors of the system factors, and process the original data to find the law of system variation, generate a data sequence with strong regularity, and then establish the corresponding differential equation model. In order to achieve the purpose of predicting the future development of things. The Verhulst model was proposed by the German scientist Verhulst. The basic idea is that the number of individual objects is exponentially increasing, and the growth rate is gradually slowed down by the surrounding environment, eventually stabilizing at a fixed value. The Verhulst model is mainly used for processes such as population and economic forecasting that may have saturation, that is, the " $S$ " type process. In the context of industrial diversification, Macau's gaming taxation is likely to be saturated in the next few decades, and the compound growth rate is likely to slow down or stagnate, so it is in line with the preconditions of the Verhulst model. The grey Verhulst model firstly accumulates the new data sequence $x^{(1)}$ according to the gambling tax or fiscal revenue and original data sequence $x^{(0)}$ and the sequence of the nearest neighbor, and then establishes the whitening differential equation of the gray Verhulst model as:

$$
\frac{d x^{(1)}(t)}{d t}+a x^{(1)}(t)=b\left(x^{(1)}(t)\right)^{2}
$$

among them Called the development coefficient, $\mathrm{b}$ is called the gray action. Solving the differential equation gives the gray Verhulst model as:

$$
\hat{x}^{(0)}(\mathrm{k}+1)=\hat{x}^{(1)}(\mathrm{k}+1)=+\hat{x}^{(1)}(\mathrm{k}+1)
$$

where $\mathrm{k}=1,2, \ldots, \mathrm{n}-1$. We used GSTA v7 software to create a grey Verhulst model of gaming revenue, public revenue and public spending from 2002 to 2016 . The model fits well and the error is small.

\subsection{ARIMA model (model C)}

The Autoregressive Integral Moving Average Model ( ARIMA ) is a well-known time series prediction method proposed by $\operatorname{Box}$ and Jenkins. $\operatorname{ARIMA}(p, d, q)$ is called differential autoregressive moving average model, AR is autoregressive, MA is moving average, $p$ is autoregressive term; $q$ is moving average term, $d$ is differential number. The model converts the non-stationary time series data into stationary data, and then returns the dependent variable to the hysteresis value and the present value and hysteresis value of the random error term. Once this model is identified, it can predict future values from the past and present values of the time series and is therefore widely used in economic forecasting. The ARIMA model is used to predict the impact of Macau's gaming tax on fiscal revenue and expenditure. It not only considers the dependence of economic phenomena on time series, but also considers the interference of random fluctuations and has better prediction accuracy.

\subsection{Integrated prediction model}

We use the independent full coefficient method to determine the weight between each model, and build a comprehensive forecasting model based on the weight. The comprehensive forecasting model can make full use of the advantages of each model to more accurately predict the impact of gaming revenue on Macau's public finances. The independence weight coefficient method determines the index weight according to the strength of the complex correlation coefficient 
between the data simulated by each model and the actual data. The higher the complex correlation coefficient, the higher the accuracy of the model simulation data, so the model is integrated. The higher the weight in the forecast. Firstly, the simulation data is calculated according to the established model, and then the complex correlation coefficient between the simulated data and the real data is obtained, and the weights of each model are obtained by normalization processing. Finally, using Eq.4, the comprehensive forecast value of gambling tax on public finance in different situations is obtained.

Comprehensive predictive value $=$ weight of model A X predictive value + weight of model $\mathrm{B} X$ predictive value + weight of model $\mathrm{C} X$ predictive value

\section{Empirical analysis}

In this paper, a linear regression model, a grey econometric hybrid model and an ARIMA model are constructed to predict, and then three models are given different weights to construct a comprehensive forecasting model to achieve higher prediction accuracy. Finally, three different scenarios are assumed and utilized. The four models are used to measure and predict the impact of gambling tax on public finance in different situations.

\subsection{Construction of the Impact Model of Gaming Industry Taxation on Public Finance}

Table 1 Regression results of the Model A and B

\begin{tabular}{l|l|l|l|l|l}
\multicolumn{9}{c}{ Unit: Thousand MOP } \\
\hline \multirow{2}{*}{ Model A } & & Constant ( c & Coefficients & Adjusted R ${ }^{2}$ & Sig. \\
\cline { 2 - 7 } & Public Income & 9589524.123 & 1.181 & 0.992 & 0.000 \\
\cline { 2 - 7 } & Public Expenditure & 15733130.731 & 0.401 & 0.618 & 0.000 \\
\cline { 2 - 7 } Model B & Public Income & 10076110.342 & 1.186 & 0.997 & 0.000 \\
\cline { 2 - 7 } & Public Expenditure & 6922054.419 & 0.650 & 0.973 & 0.000 \\
\hline
\end{tabular}

Based on Eq.1, using the annual data of Macau from 2002 to 2016 for linear regression, the results are shown in Table 1 . For every $1,000 \mathrm{MOP}$ increase in gaming tax revenue, public income will increase by 1,180 MOP and public expenditure will increase by $401 \mathrm{MOP}$. The simulated data calculated by Formula 2 is estimated by least squares method to obtain the mixed model of gray economic quantity. The regression results show that every 1,000 MOP increase in gaming tax will increase public income by $1186 \mathrm{MOP}$ and public expenditure by $650 \mathrm{MOP}$. Good and remarkable.

Using the Macau gaming tax from 2002 to 2016 as an independent variable, the fiscal revenue and expenditure as a dependent variable, usingSPSS19.0 software for ARIMA modeling. According to the characteristics of the autocorrelation function and the partial autocorrelation function of the transform series, the ARIMA ( $0,1,0)$ model is determined by testing. It can be seen from the test results that the parameter estimation all passes the significance test and the fitting degree is good.

Calculated by Eq. 4 , the weights of Models 1, 2, and 3 in the comprehensive prediction model are $0.34,0.32$, and 0.34 , respectively .

\subsection{Forecast of the Impact of Gaming Industry Taxation on Public Finance in Different Situations}

In order to analyze the impact of gambling tax on fiscal revenues and expenditures in different contexts, we presuppose that:

1), 2020-2030 gambling revenues were 200 billion, 300 billion and 400 billion MOP. Based on the current $39 \%$ betting duty rate, it can be calculated that there will be three different scenarios for gambling taxation between 2020 and 2030 , namely, the situation of one annual tax revenue of 78billion, the situation of two 117 billion and the situation of three 156 billion.

2). External factors such as the macroeconomic and economic conditions of the world and the Mainland, the management level of the Macau government and the betting duty rate remain unchanged during the estimation period. 
3). All data are calculated in present value and inflation is not considered.

Through the model one, two and three established above, the impact of gaming revenue on fiscal revenue and expenditure in different scenarios is predicted. The results are shown in Table 2:

Table 2 Forecast results of fiscal revenue and expenditure in different situations

Unit: 100 million MOP

\begin{tabular}{l|l|l|l|l}
\hline Situation & & Scenario 1 & Scenario 2 & Scenario 3 \\
\hline \multirow{2}{*}{ Model A } & Public Income & 1017.08 & 1477.67 & 1938.26 \\
\cline { 2 - 5 } & Public Expenditure & 470.11 & 626.5 & 782.89 \\
\hline \multirow{3}{*}{ Model B } & Public Income & 1025.84 & 1488.38 & 1950.92 \\
\cline { 2 - 5 } & Public Expenditure & 576.22 & 829.72 & 1083.22 \\
\hline \multirow{3}{*}{ Model C } & Public Income & 1020.00 & 1480.00 & 1940.00 \\
\cline { 2 - 5 } & Public Expenditure & 470.02 & 626.36 & 782.7 \\
\hline
\end{tabular}

According to the prediction results of Models 1, 2 and 3, when the gaming revenue is 200 billion MOP, the three models predict the income is about 102 billion MOP, and the expenditure is about 50 billion MOP. When gaming revenue at 300 billion MOP, 148 billion MOP in public revenue and expenditure between 600-800 million, when gaming revenue of 4,000 billion MOP, 194 billion MOP expenditure of public revenue between 780-1083 billion MOP .

Table 3 Comprehensive forecast results of fiscal revenue and expenditure

Unit: 100 million MOP

\begin{tabular}{|c|c|c|c|c|c|c|c|}
\hline & & \multicolumn{2}{|l|}{ Scenario 1} & \multicolumn{2}{|l|}{ Scenario 2} & \multicolumn{2}{|l|}{ Scenario 3} \\
\hline & & $\begin{array}{l}\text { Predictive } \\
\text { value }\end{array}$ & $\begin{array}{l}\text { Growth } \\
\text { rate }\end{array}$ & $\begin{array}{l}\text { Predictive } \\
\text { value }\end{array}$ & $\begin{array}{l}\text { Growth } \\
\text { rate }\end{array}$ & $\begin{array}{l}\text { Predictive } \\
\text { value }\end{array}$ & $\begin{array}{l}\text { Growth } \\
\text { rate }\end{array}$ \\
\hline \multirow{5}{*}{$\begin{array}{l}\text { Integrated } \\
\text { Prediction } \\
\text { Model }\end{array}$} & Public Income & 1020.88 & $-1.96 \%$ & 1481.89 & $3.31 \%$ & 1942.9 & $4.11 \%$ \\
\hline & Public Expenditure & 504.03 & $-11.62 \%$ & 691.48 & $-1.96 \%$ & 878.93 & $0.44 \%$ \\
\hline & Fiscal Surplus & 516.85 & $16.69 \%$ & 790.41 & $12.28 \%$ & 1063.97 & $10.04 \%$ \\
\hline & $\begin{array}{l}\text { Public Expenditure } \\
\text { Income }\end{array}$ & $49.37 \%$ & Null & $46.66 \%$ & Null & $45.24 \%$ & Null \\
\hline & $\begin{array}{l}\text { Gaming Tax / Public } \\
\text { Income }\end{array}$ & $76.40 \%$ & Null & $78.95 \%$ & Null & $80.29 \%$ & Null \\
\hline
\end{tabular}

By using the prediction results of the three models and giving different weights, more accurate comprehensive prediction results can be obtained. According to the weights calculated by the comprehensive forecasting model, the comprehensive forecasting results are obtained. As can be seen from Table 3, assuming that the scale of gaming is 200 billion MOP, the annual public revenue and expenditure will remain at 102billion and 50.4 billion MOP. Based on 2016 growth rates of $-1.96 \%$ and $-11.62 \%$, the corresponding fiscal surplus (public revenue minus public expenditure) was 51.7 billion MOP. Public expenditure as a percentage of public income ( To $49.37 \%$, while the proportion of public gaming tax revenue $(76.40 \%$. Assuming that the scale of gaming is maintained at 300 billion MOP, the annual public revenue and expenditure will remain at around 1288.2 billion and 69.1 billion MOP, based on a compound growth rate of $3.31 \%$ and $-1.96 \%$ in 2016, and a corresponding fiscal surplus of \$ 79billion. . Public expenditure accounted for $46.66 \%$ of public income, while gaming revenue accounted for $78.95 \%$ of public revenue. Assuming that the scale of gaming is maintained at 400 billion MOP, the annual public revenue and expenditure will remain at 194.3 billion and 87.9 billion MOP, based on the growth rate of $4.11 \%$ and $0.44 \%$ in 2016, and the corresponding fiscal surplus will be 106.4 billion MOP in public expenditure. The proportion of public income is $45.24 \%$, while gaming revenue accounts for $80.29 \%$ of public income. It can be seen from the forecast that public expenditure as a percentage of public revenue will decline according to the increase in gaming revenue, and the proportion of gaming revenue to public revenue will increase with the increase in gaming revenue. 


\section{Summary}

Through quantitative analysis, we deeply analyzed the impact of gambling tax on public finance, predicted the trend of future public expenditure in Macau, measured the public income needed to meet the expenditure, and predicted the future development scale of the gaming industry from the perspective of public finance.

Correlation analysis and grey correlation analysis also show that the growth of gambling tax revenue will bring about significant growth in various fiscal revenues. The government's expenditure on administrative expenditure, infrastructure and social welfare is relatively less affected by gambling taxation. On the other hand, the difference in the correlation between gambling tax and budget expenditure and actual expenditure also indicates that there is room for improvement in the implementation of government budget.

By constructing a linear regression model, a grey econometric hybrid model, an ARIMA model, and a comprehensive forecasting model, three different scenarios are assumed to predict the impact of gaming taxation on public finance in different contexts. From the forecast results, it can be seen that the scale of gaming is maintained at 200 billion MOP, and the annual public revenue and expenditure will remain at 102 billion MOP and 50.4 billion MOP. Assuming that the scale of gaming is maintained at 300 billion MOP, the annual public revenue and expenditure will remain at around 1288.2 billion MOP and 69.1 billion MOP. Assuming that the scale of gaming is maintained at 400 billion MOP, the annual public revenue and expenditure will remain at 194.3 billion and 87.9 billion MOP. It can be seen from the forecast that public expenditure as a percentage of public revenue will decline according to the increase in gaming revenue, and the proportion of gaming revenue to public revenue will increase with the increase in gaming revenue.

\section{References}

[1] Wang Xuehong: "Analysis of the Reform of Macau Gaming Franchise", "China Finance", 2013 , No. 6 .

[2] Guo Xiaodong, Zhang Dongming: “Analysis of the Changing Direction of Macau's Financial Development”, Guangdong Social Sciences , No. 3, 2000 .

[3] Lv Kaiyan, Yang Daowei: "Analysis and Suggestions on the Characteristics of Fiscal Expenditure in Macau”, Guangdong Social Science ,No.6, 2008 .

[4] Guo Xiaodong, Zhou Yan and Yang Daowei: "The Role and Function of Macau's Fiscal Policy", Hong Kong and Macau Watch , No. 3, 2001.

[5] Yuan Zhangping and Liu Yang: "Study on the Appropriate Scale of Gaming Industry and Diversification of Industrial Structure-Taking Macau as an Example”, Social Science Literature Publishing House, 2017.

[6] Luo Shiliang: “Macau Gaming Franchise Tax Research”, Jinan University, 2005.

[7] Zhang Tao: "Interactive Analysis of Macau's Financial Situation Pre-Economic Growth", Business Research , No. 11 of 2016 .]8] Cheng Danhong: "Comparative Analysis and Enlightenment of Public Finance Management Models in Hong Kong, Macau and Taiwan”, Wuhan University of Science and Technology, 2003.

[8] Chen Weibin: "Macau fiscal policy and fiscal reserve system research", Fudan University, 2013. 